\title{
Temas de Psicosociología del trabajo
}

\section{Labor issues Psychosociology}

\author{
Marcos de Antonio García \\ Universidad Complutense. Escuela Nacional de Medicina del Trabajo. \\ Unidad de Ergonomía. Madrid.
}

Recibido: 02-09-10

Aceptado: 21-10-10

\author{
Correspondencia: \\ Marcos de Antonio García \\ Urb. Prado Largo, 63 \\ 28223 Pozuelo de Alarcón (Madrid). España. \\ Tfno.: 913520804 \\ e-mail: marcosdeantonio@yahoo.es
}

Desde el punto de vista psicosociológico, el trabajo puede definirse como una situación humana ante la cual el hombre responde con un cierto tipo de conducta. Pero para tratar de describir el trabajo hemos de tener en cuenta sus tres aspectos principales: El personal, el productivo y el social.

1) En cuanto al trabajo como actividad personal, el que trabaja es el ser humano con toda su integridad, y en el trabajo forja su vida, desarrolla su personalidad e influye en la vida y personalidad de los demás. Si bien es cierto que el trabajo depende de la personalidad del trabajador, no es menos cierto que la personalidad del trabajador depende a su vez, del trabajo; por tanto, el trabajo es una forma de hacerse a sí mismo y de hacer a los demás, y en este sentido un trabajo será tanto más eficaz en la medida en que ofrezca al trabajador la posibilidad de expresar su personalidad, desarrollándola y enriqueciéndola.

2) El trabajo, bajo el enfoque de actividad productiva. El hombre, al trabajar, siempre produce algo que satisface o pretende satisfacer una necesidad, conveniencia o demanda de la sociedad. En este aspecto un trabajo será tanto más eficaz cuanto más favorezca, mediante la expresión y el desarrollo de la personalidad del trabajador, una producción elevada.

3) Pero el trabajo es también y quizás sobre todo, una actividad social, el hombre trabaja en una situación interpersonal y social, trabaja con otros y su trabajo también depende de los otros, de las relaciones humanas que existan en la empresa, del sentido que al trabajo se dé en la sociedad en que la empresa se integre, de la estructura general de esa sociedad, y también de su relación con los clientes externos. El trabajo en este sentido es una forma de convivencia y una auténtica escuela de formación social.

Analizados brevemente los tres aspectos principales del trabajo, podemos describirlo psicosociológicamente con la definición que nos ofrece el Profesor Mariano Yela (1) : "El trabajo eficaz será aquella situación humana en la que el trabajador consiga una alta producción a través de la expresión y desarrollo de su personalidad, en un ambiente técnico e interpersonal que favorezca su sana incorporación a un grupo y a una sociedad".

Es obvio, el ser humano no vive solo -necesita de los demás para asegurar su vida-, se encuentra reunido y/o asociado con otros muchos seres humanos, de forma que cada persona pertenece a una gran variedad de grupos humanos, en el seno de los cuales transcurre la mayor parte de su vida familiar, social y profesional, aunque a veces no nos demos cuenta de que pertenecemos a tantos grupos y nos dejemos llevar y guiar, sin percibir de la influencia que sobre nosotros ejercen y sin preocuparnos demasiado del papel que en ellos desempeñamos.

Vemos, por tanto, que el hombre vive continuamente agrupado y formando parte de una serie de asociaciones o comunidades. Pero conviene aclarar este concepto y definir lo que verdaderamente entendemos por grupo humano. 
Una serie de personas forman un grupo cuando están relacionadas por contactos directos, múltiples, frecuentes, sostenidos a lo largo del tiempo y encaminados a un fin común. Este último aspecto es trascendental. Por lo tanto, no puede considerarse grupo humano a una pareja sin hijos (no existen contactos múltiples), ni a una reunión accidental (no hay contactos sostenidos a lo largo del tiempo), ni a una masa de público (no hay contactos directos entre los miembros del grupo), y desde luego, sus objetivos no están encaminados hacia un objetivo común.

El hombre tampoco trabaja solo, salvo casos totalmente excepcionales, sino integrado dentro de un grupo humano y formando parte de él, es decir, en compañía de otros y subordinado a otras personas. Su comportamiento y eficacia dependerán, por tanto, de su adaptación a ese grupo, y sus satisfacciones e insatisfacciones más profundas son producto de sus contactos personales con los demás miembros del grupo.

Forman parte de los conceptos clásicamente aceptados las tesis adoptadas por el Congreso del Centro Suizo de Estudio y de Información sobre la Comunidad en el Trabajo, donde se decía (2):

"La comunidad, por la que podemos entender el conjunto de trabajadores que tienen las mismas necesidades vitales y están comprometidos en el mismo destino, es tan necesaria al hombre como su libertad. La comunidad debe:

- Permitir a cada persona su pleno desenvolvimiento y el cumplimiento de su fin personal superior.

- Basarse en los sentimientos de afecto y de respeto hacia la persona humana, así como el de la justicia, fuera de la cual no es posible ninguna comunidad ni ninguna verdadera libertad.

- Incorporar material y moralmente a todos sus miembros.

- Regirse por seres libremente consentidos."

Toda Empresa es un grupo humano de trabajo. No se la puede considerar como una suma de individuos aislados, sino como un conjunto de trabajadores integrados en grupos diversos (secciones, servicios, talleres, departamentos, niveles, empresa). El funcionamiento y eficacia de la Empresa depende del funcionamiento y eficacia de los grupos que la componen y del grupo total que ella misma constituye.

Todo grupo humano se caracteriza por su estructura y su dinamismo, y la Empresa a su vez, y como no puede ser de otra manera, también tiene su estructura y su dinamismo dado precisamente que es un grupo humano, y esta estructura y este dinamismo dependen de las relaciones interpersonales y colectivas de sus grupos. Estas relaciones constituyen la estructura social de la Empresa.

Toda organización, y por tanto también la Empresa, tiene una estructura legal o formal a la que se incorpora el trabajador cuando ingresa, y éste, tiene derecho a conocer quiénes forman y cuál es la estructura de las direcciones o divisiones, departamentos, secciones, talleres, servicios, etc., según sea su organización, y de otra estructura que debe poder verse reflejada en los organigramas. Cuando un trabajador ingresa en una empresa se incorpora a esta estructura formal o legal, ya que ingresa en uno de los talleres, secciones o departamentos que la forman.

Pero a lo que verdaderamente se incorpora el trabajador cuando ingresa, en lo que verdaderamente se integra, es en el grupo humano que forma con sus compañeros de trabajo, con los que está en contacto diario y directo, y con su jefe inmediato. De forma que del contacto diario entre los trabajadores surge espontáneamente un nuevo y diferente grupo que adquiere unas características y manifestaciones específicas, de forma que, en toda empresa co-existen dos estructuras diferentes:

- Estructura legal o formal.

- Estructura informal o espontánea. 
En la práctica, lo que verdaderamente interesa conocer son las manifestaciones del grupo espontáneo ya que ellas condicionan las actitudes y la conducta de cada individuo y por ende de la empresa; pero este es otro tema que comentaremos en próximos trabajos.

El mayor inconveniente para la eficacia del trabajo es que los tres aspectos o fines principales -desarrollo de la personalidad, incorporación social y alta producción- están en casi continuo conflicto, pues no en balde toda situación laboral es de por sí inestable y cualquier modificación en ella plantea una serie de nuevos problemas a resolver.

Es por ello que la tarea psicosocial del trabajo es siempre interminable, porque interminables son y serán siempre los problemas que ofrece la empresa en su devenir diario, y exigen el compromiso de todos los responsables de los entes humanos que la viven.

Pero en este aspecto ¿cuáles son las contribuciones que la psicosociología nos puede aportar en el ámbito de la empresa?

Éste es un aspecto de reflexión importante, puesto que no sólo plantea la necesidad de clarificar objetivos, recoger los diferentes cuerpos teóricos y delimitar el rigor científico de los medios, técnicas y procedimientos empleados, sino que también plantea un aspecto esencial: el de su utilidad práctica, es decir, su aporte real a la solución de los problemas del trabajo en la industria. En este sentido, recordemos las palabras de Ferrarotti, citando a Tiffin en su Industrial Psychology : "Un ejecutivo que quiera desarrollar su actividad puede encargar diez, cien y hasta mil máquinas nuevas de un tipo determinado, con la seguridad de que esas máquinas se construirán de la misma manera, conseguirán el mismo rendimiento y darán productos uniformes. Pero el obtener igual número de operarios capaces de hacer funcionar estas máquinas con un grado de competencia homogénea y satisfactoria es algo muy distinto. Todos los técnicos directivos saben que máquinas idénticas dan raramente una producción igualmente idéntica cuando están sometidas al control de operarios distintos. Los hombres se diferencian entre sí por su naturaleza, por su formación, por sus estudios y sus gustos. Un mismo trabajo puede ser realizado satisfactoriamente por un obrero y con no menos perfección por otro utilizando manera y métodos heterodoxos, mientras que un tercero consigue resultados negativos utilizando modos estrictamente ortodoxos, y su ejecución puede proporcionar gran satisfacción personal a un operario, constituir un trabajo monótono y aburrido para otro y superar por completo la capacidad de un tercero" ${ }^{2}$.

En este campo de aplicación, las aportaciones prácticas, y en general reconocidas por la industria, son diversas: Métodos de selección (entrevista, cuestionarios, test de medida de aptitudes y personalidad... ), cualificación de las tareas, rendimiento y valoración de las mismas, formación de las personas, métodos de atribución de salarios, orientaciones individuales, programación de carreras, etc.; aunque en realidad, puede decirse que, al menos en España, el papel de los expertos en la industria, en muchos casos, se ha quedado en una sola de estas facetas, la selección del personal de nuevo ingreso.

1. Ferrarotti: Hombres y máquinas en la sociedad industrial. Labor, Barcelona, 2004.

2. Estudios suizos, p. 87. La Baconniére, Neuchatel. Octubre 1947. 